\title{
Image-guided navigation systems for interstitial brachytherapy
}

\author{
Yan-Yan $\mathrm{Hu}^{1}$ and Xiao-Ling $\mathbf{Y u}^{1}$ \\ ${ }^{1}$ Department of Interventional Ultrasound, Chinese PLA General Hospital, Beijing, China \\ Correspondence to: Xiao-Ling Yu, email: dyuxl301@aliyun.com \\ Keywords: navigation, imaging modalities, interstitial brachytherapy, fluorescence molecular imaging, image-guided \\ Received: October 24, $2016 \quad$ Accepted: June 02, $2017 \quad$ Published: January 02, 2018 \\ Copyright: Hu et al. This is an open-access article distributed under the terms of the Creative Commons Attribution License 3.0 (CC BY 3.0), \\ which permits unrestricted use, distribution, and reproduction in any medium, provided the original author and source are credited.
}

\begin{abstract}
Interstitial brachytherapy has shown quite promising therapeutic effects in the treatment of tumors in various body regions. Prior to the navigation techniques with quantitative imaging feedback during the procedure, the safety and accuracy of interstitial brachytherapy mainly depended upon the operator's experience, spatial skills and mind reconstruction of the anatomical structures. Different navigation systems have been reported to be experimented on various phantoms and clinically applied in the brachytherapy of many anatomic sites. The numerous advancements of navigation systems integrated with multiple imaging modalities increase accuracy and standardization of the brachytherapy procedure, guarantee clinical effects and even enable less experienced operators to deliver a precise procedure. This article reviews the existing navigation systems and techniques for brachytherapy and discusses the relevant clinical applications.
\end{abstract}

\section{INTRODUCTION}

Brachytherapy is a form of radiotherapy which places radioactive sources permanently into the tumor or region of interest or temporarily into body cavities using afterloading techniques. In the past 20 years, interstitial brachytherapy has shown quite promising therapeutic effects in the treatment of tumors in various body regions. When tumors are unresectable, recurrent, with positive surgical margins or located nearby risk structures, interstitial brachytherapy can be used as a complementary therapy for surgery, chemotherapy, external beam radiotherapy and interventional techniques such as RFA (Radiofrequency Ablation), MWA (Microwave Ablation) and TACE (Transhepatic Arterial Chemotherapy Embolization) [1-5]. The most widely used form of interstitial brachytherapy is probably the transrectal ultrasound (US)-guided prostate brachytherapy [6, 7]. 5-10 years of follow-up shows that the clinical outcomes of interstitial brachytherapy for early-stage prostatic cancer are comparable to those of surgery [8-10].

However, the accuracy of brachytherapy can be decreased by many factors. For example, the transperitoneal needle insertion may cause organ movement and distortion, which often leads to seed misplacement and dosimetry errors $[11,12]$ Prior to the navigation techniques with quantitative imaging feedback during the procedure, the safety and accuracy of brachytherapy mainly depend upon the operator's experience, spatial skills and mind reconstruction of the anatomical structures. Therefore, image-guided navigation systems, which can provide the spatial orientation of the tumor and the structures buried or beside the tumor in interstitial brachytherapy, is of higher demand. Nowadays, more and more navigation systems have been developed and put into use in clinical procedures, such as conventional and robotic surgery, endoscopy, laparoscopy, radiotherapy and interventional procedure. On the basis of existing and newly developed navigation technologies, different navigation systems have been reported to be experimented on various phantoms and clinically introduced into the brachytherapy treatment of many anatomic sites, such as prostate, endometrium and cervix [13], head and neck [14], breast [15], lung [16], liver, etc. The numerous advancements of navigation systems integrated with multiple imaging modalities increase accuracy and standardization of brachytherapy, guarantee clinical effects and even enable less experienced operators to deliver a precise procedure.

A literature search was performed on PubMed, EMbase for papers between January, 2000 and March, 2016 with no language restrictions. We used "brachytherapy", "seed implantation", "navigation", 
"image fusion", "radioactive particles" as search terms. We prioritized publications from the past 5 years which had significant impact and introduced new ways of thinking without excluding influential and commonly referenced older publications. We searched all types of publications, including review articles, case reports and abstracts, to provide readers with more details and more references. This article will review the published literature, describe the existing navigation systems and techniques for brachytherapy, generate data tables and graphs, and discuss the relevant clinical applications.

\section{Navigation}

The concepts of image-guided navigation can be traced back to last century starting with a study in 1908 , which introduced stereotactic frames [17]. The software of image-guided navigation system is the basis of every navigation system. It can integrate tracking information, correlate quantitative imaging with tracking data and show real-time updates of the position of the instrument and status of the procedure. Open-source software such as MITK, IGSTK and 3D Slicer, with freely available source code and sharable common infrastructure, can be modified to carry out new applications [18-21]. Therefore, multiple research groups can avoid repeated work like reinventing the software while the modified navigation systems can be adapted to image-guided interstitial brachytherapy. Krempien et al. [22] described an adaption of a commercially available surgical planning and navigation system, Surgical Planning and Orientation Computer System (SPOCS; Aesculap, Tuttlingen, Germany) to brachytherapy. The results of their phantom experiments including 250 single-needle applications and 20 multipleneedle volume implantations showed the mean target registration error (TRE) for single-needle applications of $1.1 \mathrm{~mm}$ (SD +/- $0.4 \mathrm{~mm}), 0.9 \mathrm{~mm}$ (SD +/- $0.3 \mathrm{~mm}$ ), and $0.7 \mathrm{~mm}(\mathrm{SD}+/-0.3 \mathrm{~mm})$ in the $\mathrm{x}, \mathrm{y}$, and $\mathrm{z}$ direction, respectively. The corresponding TRE was $1.6 \mathrm{~mm}$ (SD +/- $0.4 \mathrm{~mm}), 1.9 \mathrm{~mm}$ (SD +/- $0.6 \mathrm{~mm})$, and $1.0 \mathrm{~mm}$ ( $\mathrm{SD}+/-0.4 \mathrm{~mm}$ ), respectively for multi-needle volume implants. The maximal deviations of the needle relative to the planned position were in the range $2.3-2.9 \mathrm{~mm}$.

In clinical practice, image-guided navigation systems can provide the operators with the position of the instrument, information on anatomical structures, spatial orientation and guide them towards the targets along a predefined trajectory by tracking of needles, ultrasound transducers or other devices. However, the accuracy of the existing navigation systems is not satisfactory. Our research team, who has carried out the procedure of permanent seed implantation for almost 10 years, is in the process of developing a $3 \mathrm{D}$ visualized, US-guided navigation system for abdominal seed implantation based on previous studies [23-25] which have presented inspiring clinical results. We expect this system for brachytherapy could decrease the standard deviation in TRE to $1 \mathrm{~mm}$. As shown in Figure 1, the typical workflow for abdominal and cervical seed implantation procedure was mapped.

\section{Treatment planning systems}

Before brachytherapy procedure, a treatment planning system (TPS) can be used to identify safe and operable needle trajectories and determine the location and number of radioactive seeds so as to achieve the calculated dosimetric goals. It is a software system which enables the anatomy visualization of the patient by $3 \mathrm{D}$ reconstruction and image fusion of the pre-acquired, imaging information from MR (magnetic resonance) or CT (computed tomography) scanners. After the procedure of brachytherapy, TPS can also be used to execute imagebased postimplant dosimetric analysis. Currently, both the AAPM (American Association of Physicists in Medicine) and ABS (American Brachytherapy Society) recommend the evaluation of postimplant dosimetry for all patients undergoing prostate brachytherapy [26-28]. A number of treatment planning systems are now commercially available. However, the weaknesses such as requirement for manual sketch, not applicable to all body parts, and not providing standard dose models for corresponding lesions limit their applications. Thus, future TPS that can handle tissue composition and density, applicator geometry, body shape and dose calculation is expected [29-32].

A simple optimization method, presented by Deufel et al. [33], was able to gain similar results compared with more complex optimization algorithms found in commercial treatment planning systems for high dose rate brachytherapy. Fonseca et al. [34] proposed a Medical Image-based Graphical platform Brachytherapy module (AMIGOBrachy), a software module capable of integrating clinical treatment plans with Monte Carlo (MC) simulations with increased accuracy and creates an efficient and powerful user-friendly graphical interface which is able to be incorporated in clinical practice. This simple method optimized conformal target coverage using an exact, variance-based, algebraic approach. It was able to acquire similar metrics such as dose volume histogram, conformity index, and total reference air kerma compared with complex optimizations for cervix, breast, prostate, and planar applicators. However, image-based conformal treatment planning is still largely constrained by the nature of dwell locations even though we can sculpt/ customize radiation dose distribution to meet different requirements and patient anatomy. In addition, there is a lack of clinical evidence which can provide a standard and optimal dose model for corresponding lesions with different therapeutic goals. Therefore, it calls for combined efforts to develop a conformal treatment planning system for various body parts supported by clinical validation of optimal dose. 


\section{Registration}

Image registration is the process of aligning preoperative coordinate systems with an intraoperative one. The overall goal of image registration applied to image-guided brachytherapy is to fuse imaging information acquired at different points in time, treatment planning and post-processing results into an integrated view during the procedure. Broadly there are two types of registration: rigid registration in which rotations between the data sets are allowed, a small shape change between acquisitions has occurred and deformations are not considered and non-rigid registration, which is required in unstable anatomical structure with elasticity and mobility such as lung, liver and cervix $[13,35]$.

In clinical practice, rigid models are widely used especially in anatomical structures enclosed by a rigid structure such as the brain or with bony landmarks such as the spine [36-38]. Detailed methodology for testing and quantifying the systemic accuracy of the rigid registration results is well established [39], and for all marker configurations, the automatic technique displayed subvoxel accuracy of marker localization (less than $0.8 \mathrm{~mm}$ ). Therefore, rigid registration tools have been included in some navigation products such as a neuronavigation system named BrainLab VectorVision which is used for implanting radioactive particles into the cranial base and orbital ape $[40,41]$. However, these rigid registration tools are not suitable for compensating the deformations observed in the soft tissues, which requires the use of deformable or non-rigid registration methods. Over the past 20 years, a large number of non-rigid registration (NRR) models have been developed. However, NRR approaches have only been applied in some research systems with preliminary results due to the challenges in algorithms, computational requirements and validation for NRR [42]. In addition, patient motion such as respiration and cardiac motion which may cause tissue deformation is also a confounding factor $[43,44]$. Respiratory motion greatly affects thoracic procedures such as brachytherapy and tumor ablation during which the lung is usually deflated, thus preoperative images are rendered ineffective for targeting the tumor. To address this issue, Naini et al. [45] presented a novel image construction technique which could predict the deformation of the lung and process the pre-operative $\mathrm{CT}$ images in order to obtain the CT images of deflated lung.

The diversity of imaging technologies being registered is another confounding factor that inhibits the maturity of the available NRR approaches for clinical applications. Modalities such as $\mathrm{CT}$ and magnetic resonance imaging (MRI) sample volumetric data in three spatial dimensions while other technologies such as B-mode US, $\mathrm{X}$-ray and fluoroscopy sample imaging data in two spatial dimensions. Registration between images of different spatial dimensionality necessitates transformation [41, 46, 47].

In the context of a common procedure of seed implantation, pre-procedural volumetric CT data and 2D US data, which represents a slice through a 3D volume

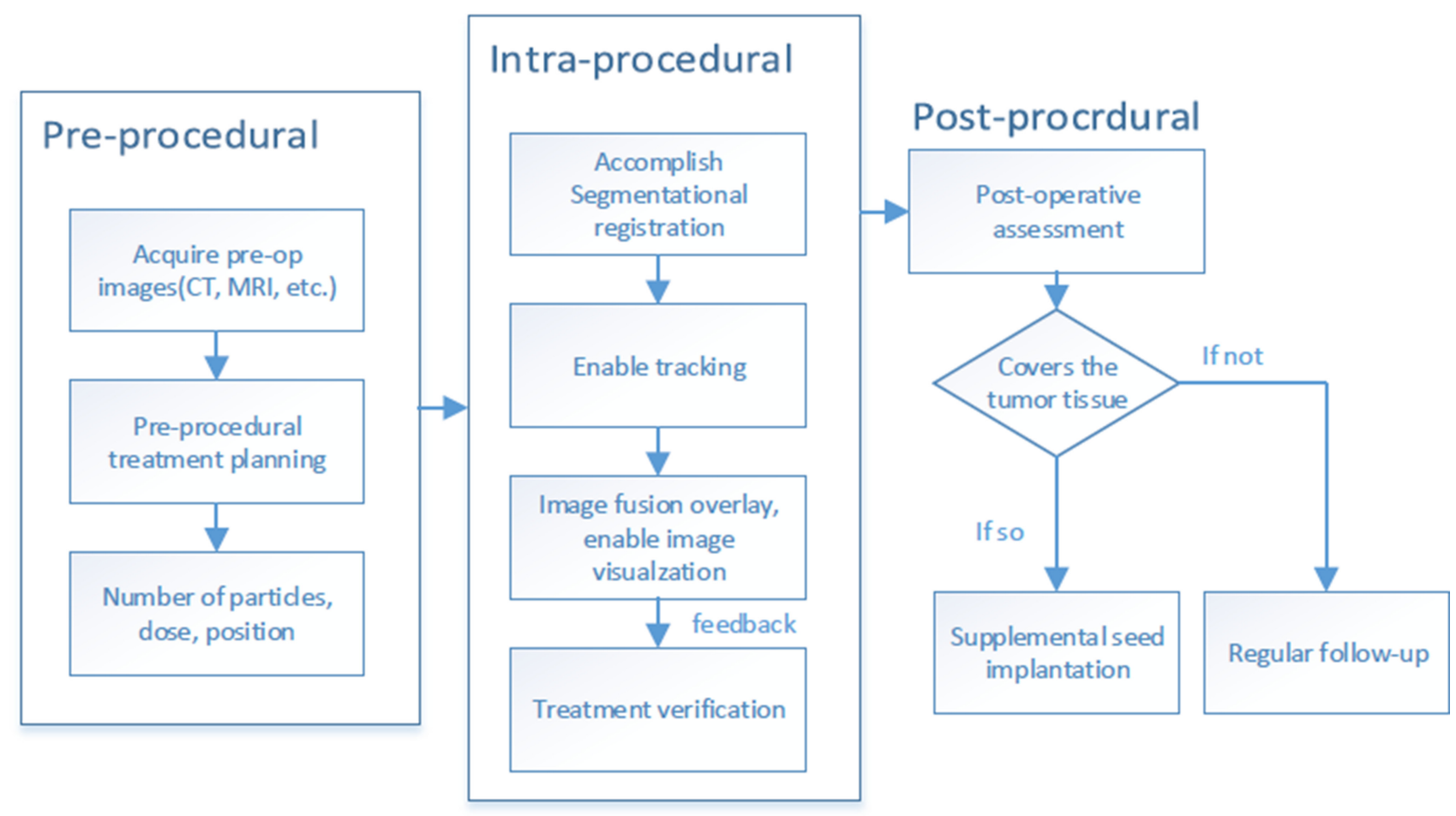

Figure 1: Typical workflow for an intraoperative navigation system for seed implantation procedure. 
will be acquired. Then an intraoperative navigation system will be applied to track the location of the US probe and slice plane relative to the three-dimensional volume, a non-rigid registration will be finally accomplished by performing either $3 \mathrm{D}-3 \mathrm{D}$ registration via creating a $3 \mathrm{D}$ US volumetric image from US slices [44] or 2D-3D registration via aligning $2 \mathrm{D}$ slice data directly with the $3 \mathrm{D}$ volume [48, 49]. Ali et al. [35] proposed a fully automatic technique to enhance the poor quality of intraoperative US images during a lung brachytherapy procedure by preprocessing the preoperative 4D-CT respiratory sequence and constructing a CT image to the lung's deflated state. They used a deformable registration/air volume estimation/ extrapolation pipeline and the output of the CT-enhanced US image was located and oriented accurately in its preoperatively processed CT counterpart. Sub-millimeter accuracy was achieved on ex vivo phantom experiments.

Numerous challenges remain to be solved for the mature applications of NRR in navigated brachytherapy. Even though the concepts and methodologies are common, the possibility of developing a single registration method is precluded by the variety of imaging modalities, involved organs and clinical applications. Research in registration, segmentation, visualization methods, and tracking for image-guided navigation systems has continued in academic and industry laboratories. The clinical demands are the mighty power to motivate refinement of the registration technology.

\section{Tracking}

The operators used to mentally register the anatomic information from offline imaging modalities to modality used for actual guiding of the procedure which might lead to inaccuracies and human errors. Tracking systems provide the major function to track the spatial position of devices relative to a patient's anatomy, thus enabling therapies and relevant devices to be accurately positioned. The two widely used techniques for brachytherapy are optical tracking and electromagnetic (EM) tracking. The commercially available tracking systems in medical use for image-guided navigation are reviewed as shown in Table 1.

The optical tracking system uses cameras to localize visual markers with a large field of view and high measurement accuracy. It is a well-established tracking modality [50]. However, the requirement for a free line-of-sight kept between the tracking devices and instruments to be tracked is its main drawback. For procedures that instruments such as needle tips, flexible endoscopes and catheters must be tracked inside the body, the applications of optical tracking systems are limited due to limited monitoring depth because of tissue absorption and scattering. Hamming et al. [51] presented a conebeam CT-guided, automatic image-to-world registration method based on an optical tracking system. This technique acquired a subvoxel accuracy $(<0.8 \mathrm{~mm})$ of marker localization for all marker configurations and decreased the standard deviation in target registration error (TRE) from $0.34 \mathrm{~mm}$ for the manual technique to $0.2 \mathrm{~mm}$ for the automatic technique $(p=0.001)$. The automatic registration of surgical tracking in 3D images was acquired within $\sim 20 \mathrm{~s}$. The results are inspiring and indicate that automatic registration has a great potential to replace conventional manual technique in image-guided navigation.

EM tracking systems localize small sensor coils, which are embedded in medical devices for tracking inside the body, in a magnetic field of known geometry provided by a field generator (FG). The advantage of EM tracking is that it can reside inside the body without requiring "line-of-sight". Boutaleb et al. [52] demonstrated the accuracy performance of an electromagnetic tracking system (EMTS), Aurora ((R)) V1 Planar Field Generator (PFG) EMTS, in brachytherapy procedures. Their experimental results showed that the positional errors were $2+/-1 \mathrm{~mm}$ in a tracking zone restricted to the first $30 \mathrm{~cm}$, the orientation errors remained low at $+/-2$ degrees for most of the measurements and the presence of typical brachytherapy components nearby the EMTS had little influence on tracking accuracy. Unfortunately, EM tracking also has some drawbacks. Some additional hardware components, such as the EM field generator, are required to place next to the patients or even be attached to them. A lot of electromagnetic tracking systems have a dynamic registration patch which can correct for organ shifts and some also provide respiratory gating which corrects for respiratory motion. The accuracy of the EM tracking system can also be compromised by metallic objects because of magnetic field distortion [53].

To address these issues, different EM tracking systems can be customized for specific clinical applications so as to minimize the drawbacks, and mental devices can be replaced by other materials such as wood or plastic or kept away from the magnetic field as far as possible [54]. Technical evaluation shows that precise EM tracking errors can be minimized to less than $1 \mathrm{~mm}$ in a suitable environment [55]. Furthermore, to increase the tracking accuracy, some research teams proposed integrating EM sensors with other technologies [53]. It is possible to use an optical tracking technique for data fusion when lineof-sight is available. For example, Matthias et al. [56] presented a new method of evaluating surgical margins intraoperatively based on (PET/CT) image fusion, using four electromagnetic trackable spheres as well as three infrared cameras.

However, most of the commercial tracking systems are still very complex to operate, hindering widespread applications in clinical workflow. Therefore, the main challenge is the development of simple and practical tracking systems that are feasible in clinical practice. Our team has developed an EM navigation system for permanent seed implantation. Equipped with a tracked ultrasound probe and sensor coils embedded in the needle 
Table 1: Representative applications of commercial tracking systems for image-guided navigation today

\begin{tabular}{|c|c|c|c|}
\hline $\begin{array}{l}\text { Tracking } \\
\text { Technology }\end{array}$ & Product & Company and Country & Medical Use \\
\hline $\begin{array}{l}\text { Electromagnetic, } \\
\text { wireless sensors. }\end{array}$ & Polhemus & $\begin{array}{l}\text { Polhemus Inc. (Colchester, VT, } \\
\text { USA) [57] }\end{array}$ & image-guided navigation \\
\hline Electromagnetic & Aurora & $\begin{array}{l}\text { Northern Digital Inc.(Waterloo, } \\
\text { ON, Canada) [58] }\end{array}$ & image-guided navigation \\
\hline Electromagnetic & microBIRD & $\begin{array}{l}\text { Ascension Technology Corp. } \\
\text { (Burlington, VT, USA) [59] }\end{array}$ & image-guided navigation \\
\hline Electromagnetic & iLogic system & $\begin{array}{l}\text { Super Dimension Inc. } \\
\text { (Minneapolis, MN, USA) [60] }\end{array}$ & Navigated bronchoscopy \\
\hline Electromagnetic & InstaTrak & $\begin{array}{l}\text { GE Healthcare.(Chalfont St. Giles, } \\
\text { Buckinghamshire,U.K.) [61] }\end{array}$ & neurosurgical and ENT interventions \\
\hline Electromagnetic & PercuNav system & $\begin{array}{l}\text { Philips Healthcare (Hamburg, } \\
\text { Germany) [55] }\end{array}$ & US-guided punctures \\
\hline Electromagnetic & $\begin{array}{l}\text { SonixGPS } \\
\text { system }\end{array}$ & $\begin{array}{l}\text { Ultrasonix (Richmond, BC, } \\
\text { Canada) }[62,63]\end{array}$ & US-guided punctures, spinal anesthesia \\
\hline Electromagnetic & $\begin{array}{l}\text { eTRAX Needle } \\
\text { Guidance } \\
\text { System }\end{array}$ & $\begin{array}{l}\text { CIVCO Medical Solutions } \\
\text { (Kalona, IA, USA) [64] }\end{array}$ & US-guided punctures, \\
\hline Electromagnetic & $\begin{array}{l}\text { a needle } \\
\text { navigation } \\
\text { extension of } \\
\text { LOGIQ E9 } \\
\text { system }\end{array}$ & $\begin{array}{l}\text { GE Healthcare (Chalfont St. Giles, } \\
\text { Buckinghamshire, U.K.) }[65,66]\end{array}$ & $\begin{array}{l}\text { US-guided interventional radiology } \\
\text { procedures }\end{array}$ \\
\hline $\begin{array}{l}\text { Optical Tracking } \\
\text { and EM tracking }\end{array}$ & Cappa C-Nav & $\begin{array}{l}\text { (Siemens AG, Erlangen, Germany) } \\
\text { [67] }\end{array}$ & $\begin{array}{l}\text { needle punctures, CT-based } \\
\text { electromagnetically guided } \\
\text { interventions }\end{array}$ \\
\hline $\begin{array}{l}\text { Optical Tracking } \\
\text { and EM tracking }\end{array}$ & $\begin{array}{l}\text { StealthStation } \\
\text { AxiEM }\end{array}$ & $\begin{array}{l}\text { Medtronic Inc. (Fridley, MN, } \\
\text { USA) [68] }\end{array}$ & needle punctures, \\
\hline $\begin{array}{l}\text { Optical active and } \\
\text { passive infrared }\end{array}$ & NDI Polaris & $\begin{array}{l}\text { Northern Digital Inc. } \\
\text { (Waterloo, ON, Canada) [69] }\end{array}$ & image-guided surgery \\
\hline Optical videometric & MicronTracker & $\begin{array}{l}\text { Claron Technology Inc. } \\
\text { (Toronto, ON, Canada) [70] }\end{array}$ & image-guided surgery \\
\hline
\end{tabular}

tip (Figure 2), this system can provide real time feedback of the position of the seeds in relation to the fused modalities, which assist the operators to implant the seeds accurately as planned.

\section{Imaging modalities}

Imaging is a fundamental tool in navigated brachytherapy. It is essential in every aspect of the procedure including preoperative diagnosis and staging, treatment planning, real-time guidance, quantitative imaging feedback, postoperative qualitative evaluation of dosimetry and follow-up observations [71, 72] (Figure 3).
The most commonly used imaging modality for brachytherapy is CT, while other imaging modalities such as US, fluoroscopy and MRI can be applied intraoperatively for imaging guidance or used for treatment planning refinement in conjunction with CT $[71,73,74]$. However, information provided by each of these modalities alone, due to their own limitations, does not meet all the requirements for brachytherapy, thus it necessitates image fusion so as to take full advantage of acquired information. Image fusion and image co-registration is the technique to merge multiple images from different imaging modalities or from the same imaging modality but acquired at different time points, to one display and align them 
spatially to each other $[75,76]$. Therefore, by the overlay of one dataset with additional second dataset or functional dataset (functional MR, SPECT, PET), multimodality image fusion can provide additional information without the physical presence of MRI, CT, PET or SPECT during brachytherapy procedure with navigation. Recently, novel imaging techniques are being developed (3D US, power Doppler US imaging, PET, MRI-MRS and CBCT are among them) and being increasingly applied in medical practice [17, 76-78]. A review of recent representative applications of navigated brachytherapy in different imaging modalities is shown in Table 2.
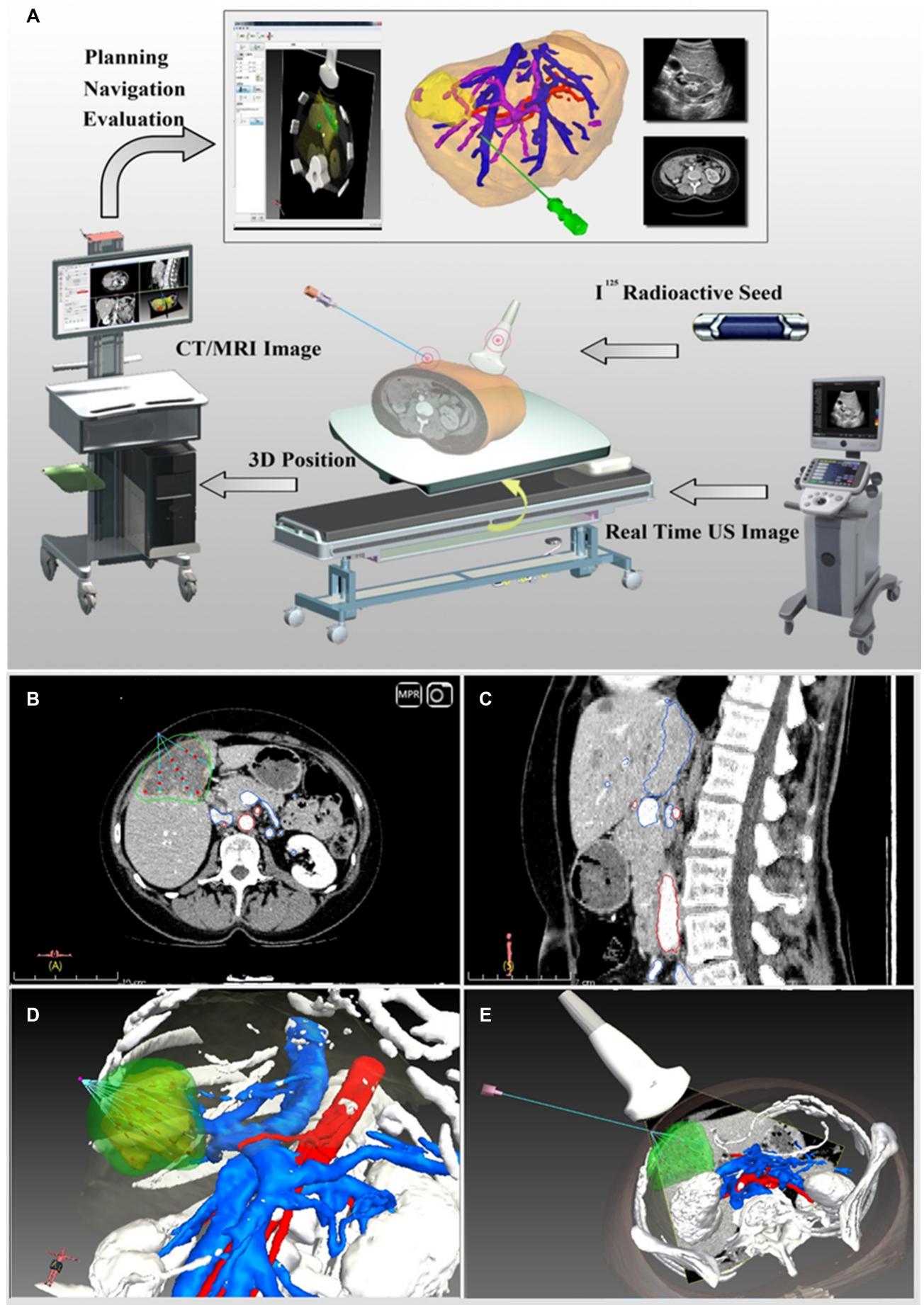

Figure 2: Electromagnetic tracking navigation system. (A) Components of image-guided navigation system incorporating electromagnetic tracking for seed implantation procedure. (B-D) User interface of the treatment planning system showing the axial, sagittal, coronal, and 3D views with radioactive seeds (red) and 100\% isodose lines (green). The treatment volume (green) covers the tumor volume (yellow) which was automatically segmented at the beginning of the planning procedure. (E) The simulation ultrasound image of the reconstructed CT image. 


\section{US or 3D Ultrasound}

Ultrasound imaging provides fast, intraoperative, real-time, and both qualitative and quantitative imaging information for treatment planning and treatment delivery in brachytherapy procedure. Developments in US imaging such as 3D US, power Doppler US or elastography $[72,83]$ and in US-based image fusion techniques open a door for the sonographer to perform interventional procedures more precisely according to the treatment plan with both anatomical and functional information. Scott et al. [84] proposed a prostate biopsy approach using real time MRI-US fusion and an adaptive focus deformable registration model on a commercially available 3D US prostate biopsy system on 29 male patients who had suspicious prostate lesions identified by Multiparametric MRI (MP-MRI). Li et al. [83] compared the accuracy of the Elekta ClarityTM 3D US system and kilo-voltage cone beam computed tomography (CBCT) (seed- and bone-based positioning) for prostate positioning in patients with prostate cancer and found out that 3D US appeared comparable to CBCT in image guidance in this retrospective study.

\section{Functional imaging modalities}

Functional imaging modalities (e.g. PET, SPECT, power Doppler US imaging, optical imaging, and MRIMRS), which have become increasingly popular in recent years, enable the assistance in target delineation, modulation of the dose and assessment of the response to the radiotherapy in radiation oncology $[56,77,78,85,86]$. With anatomical, functional and metabolic information, these functional imaging modalities open a new dimension to resolve ambiguities in anatomical imaging, map tumor cells, quantify partial organ function, and sculpt the dose of radiation in the treated volume precisely [87].

The Key Laboratory of Molecular Imaging, Chinese Academy of Science (CAS) has recently developed an advanced Optical Multimodality Molecular Imaging

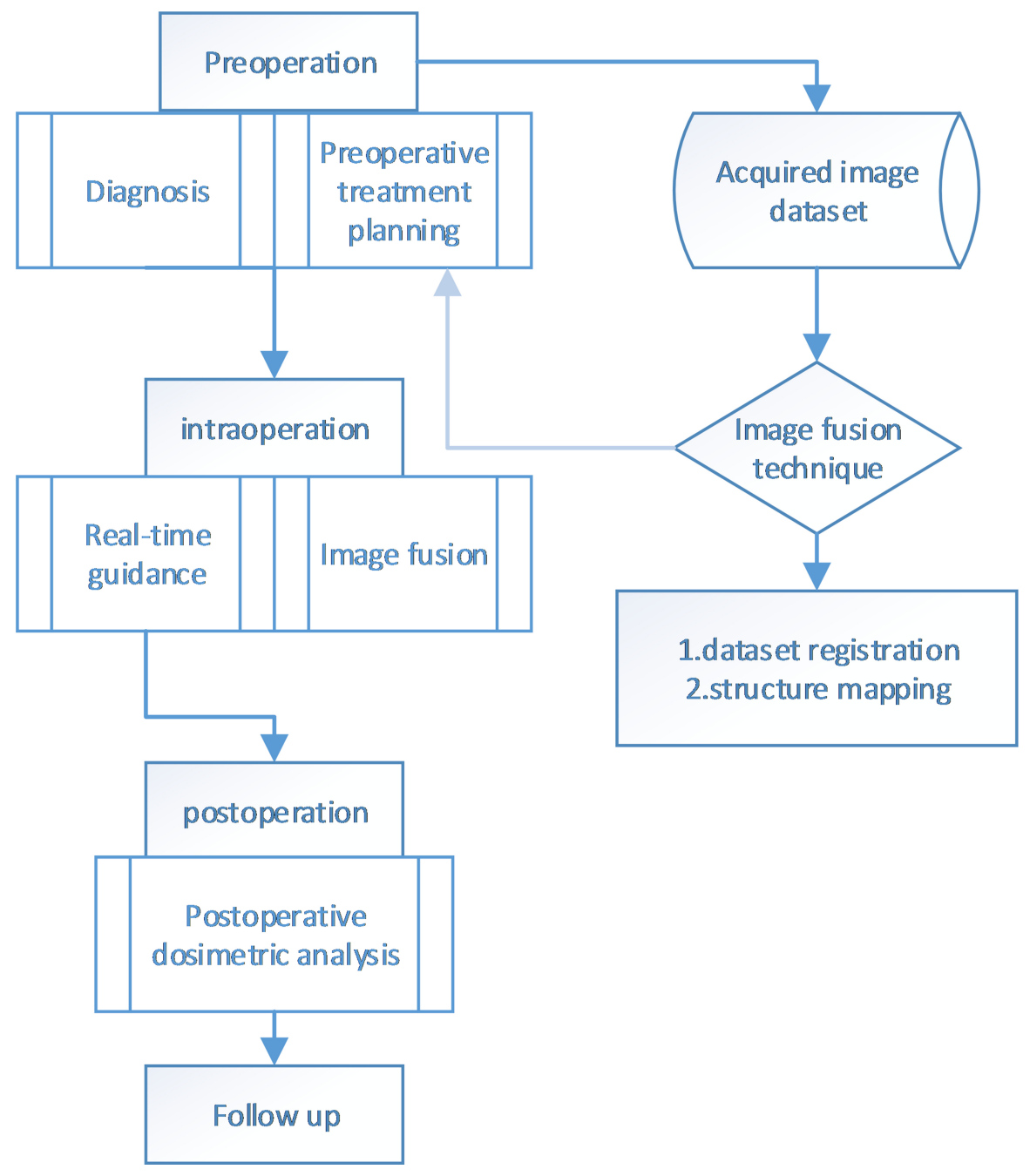

Figure 3: Role of imaging in image-guided brachytherapy procedure. 
Table 2: Representative applications for image-guided navigation systems and image-fusion techniques in brachytherapy

\begin{tabular}{|c|c|c|c|c|c|}
\hline Author (reference) & Year & $\begin{array}{l}\text { Patients } \\
\text { number }\end{array}$ & Indication & $\begin{array}{l}\text { Imaging } \\
\text { modalities }\end{array}$ & Navigation \\
\hline Bentsion et al. [79] & 2006 & 15 & Brain tumors & $\mathrm{CT}$ and MRI & $\begin{array}{l}\text { "Stryker" navigation station; } \\
\text { "Abacus" system (Dosimetric } \\
\text { planning) }\end{array}$ \\
\hline Zhenjia L et al. [16] & 2007 & 16 & Lung cancer & $\mathrm{CT}$ & optical navigation system \\
\hline Ricke et al. [71] & 2010 & 104 & Liver cancer & MR & \\
\hline $\begin{array}{l}\text { Katayama et al. } \\
{[77]}\end{array}$ & 2011 & 50 & $\begin{array}{l}\text { Prostate cancer } \\
\text { (postimplant } \\
\text { dosimetry) }\end{array}$ & $\begin{array}{l}\mathrm{T} 2^{*}-\mathrm{WI} / \mathrm{T} 2-\mathrm{WI} \\
\text { fusion-based }\end{array}$ & $\mathrm{T} 2^{*}$-WI/T2-WI fusion \\
\hline Li et al. [80] & 2013 & 24 & Nsclc & CT fluoroscopy & SIRPS \\
\hline Tagliaferri et al. [81] & 2015 & 9 & $\begin{array}{l}\text { Recurrent sinonasal } \\
\text { and nasopharyngeal } \\
\text { tumors }\end{array}$ & $\begin{array}{l}\text { Endoscopy-guided } \\
\text { brachytherapy (BT) }\end{array}$ & $\begin{array}{l}\text { Electromagnetic navigation } \\
\text { guidance }\end{array}$ \\
\hline Zhang et al. [72] & 2015 & & Prostate cancer & $\begin{array}{l}\text { 2D US and 3D MR } \\
\text { Image Regidtration }\end{array}$ & $\begin{array}{l}\text { A 2-step spatial registration } \\
\text { method }\end{array}$ \\
\hline Pouw et al. [82] & 2016 & 20 & $\begin{array}{l}\text { Nonpalpable breast } \\
\text { cancer }\end{array}$ & $\begin{array}{ll}3 \mathrm{D} & \text { freehand } \\
\text { SPECT } & \end{array}$ & Optical tracking system \\
\hline
\end{tabular}

Nsclc $=$ Non-small cell lung cancer; SIRPS = Seed Interstitial Radiotherapy Planning System; 3D = Three-dimensional; $\mathrm{SPECT}=$ single photon emission computed tomography.

system for Small Animal Imaging. A crucial feature of this system is the capability to acquire multimodality image data including BLT, FMT, PET, MRI and CT and reveal the anatomical, functional and metabolic activity simultaneously in the same device. Using this device, operators can localize viable tumor tissue preoperatively and ensure the complete treatment by visualization of any residual cancer tissue. The fast development of new multi-modality molecular probes or PET tracers also raise the possibility of a shift from anatomical imagingbased to molecular imaging-based boundary delineation, which contributes to an improvement of curative effects in interventional practice $[56,78]$.

Take optical-CT dual-modal molecular imaging probe for example, the local injection of this fluorescent probe can increase the enhancement of CT images, resulting in accurate segmentation, reconstruction and registration because of the clear delineation of the irregular tumor margin. Besides, fluorescence imaging-navigated brachytherapy can assist the operators to deliver the brachytherapy procedure with real-time adjustment of the planning according to the process of the procedure, precise localization of tumor margins that can be seen through the skin (especially for superficial malignancies such as cervical lymph node metastases) and accurate identification of metastatic lymph nodes [88], resulting in reduced number of needle puncture, operating time, incidence of complications and increased one-treatment successful rate. Therefore, fluorescence imaging-navigated brachytherapy, with tremendous potential for navigated brachytherapy, might become the future trend of the development.

\section{MRI}

MRI provides a 3D dataset, excellent soft tissue contrast, function of staging and arbitrary multiplanar reconstruction, allowing a superior delineation of normal tissues and tumors over CT and US [89]. MRI has been reported to be used in many interventional procedures such as biopsies, thermal therapy or brachytherapy in many sites $[40,71,84,90,91]$. A few articles have reported various experiences using MRI for brachytherapy and the major indications are for gynecologic and prostate cancers [91-95]. Findings of a study by Buch et al. suggested that the volume contours derived from $\mathrm{CT}$ was overestimated compared to that from high resolution contrast enhanced magnetic resonance imaging (HR-CEMRI) in 11 postbrachytherapy prostate cancer patients [92]. Viswanathan et al. reported that CT-based scans at brachytherapy showed wider target contours than MRI in cervical cancer [96]. Thus, MRI remains the gold standard for tumor contouring in image-guided brachytherapy $[96,97]$.

However, it is challenging to ensure that all the devices for brachytherapy are safe for use in high magnetic field and the acquisition of MR image is acceptable due to the different optimal pulse sequences between the soft tissue and the applicators [98]. Current solutions are to make MR compatible paramagnetic or some 
nonmetallic (plastic) devices and titanium applicators and seeds [91]. Further efforts to exploit alternative MR compatible materials, MR compatible markers, new sequences and reconstruction methods of applicator and seed visualization are required for MRI-based guidance and postimplant dosimetry assessment [92, 99-101]. So far, real-time MRI guidance is not generally used except at some major medical centers that have MR scanners available for brachytherapy procedures.

\section{CBCT}

CBCT is an imaging technique which consists of a $\mathrm{C}$-arm equipped with a flat panel detector and a cone beam $\mathrm{X}$-ray. This imaging modality, which allows low radiation exposure doses, accurate 3D volumetric datasets and the possible use of dedicated planning and navigation software, is increasingly accessible in navigated brachytherapy.

Various experiences of the implementation of CBCT in brachytherapy have been reported, including 3D planning, assistance in needle placement, intraoperative dosimetric assessment and reconstruction of implanted seed positions and orientations [102-107]. Amat di San Filippo et al. [107] introduced a new method to obtain the precise segmentation of the implanted radioactive seeds in C-arm images which was validated to be suitable for integration in the dynamic dosimetry workflow during prostate brachytherapy by the clinical datasets. The implanted seeds were delineated by a region-based implicit active contour approach. The iodine implants were segmented by a template-based matching whereas the palladium seed clusters were resolved by a K-means algorithm. The results suggested that the automatically detected rates of the implanted iodine and palladium seeds were both $98.7 \%$ and the false-positive rates of iodine and palladium seeds were $1.7 \%$ and $2.0 \%$, respectively. $\mathrm{Li}$ et al. [83] found out that the discrepancy between bonematch in CBCT and 3D US for prostate positioning was not significant and the discrepancy between seed-match in CBCT and 3D US was significant only in the longitudinal direction which is $-1.9+/-2.3 \mathrm{~mm}$. Experiences of other CBCT-based interventional procedures such as ablation and biopsy [108, 109] can be borrowed in performing navigated brachytherapy in many other sites such as the liver, lungs and metastatic lymph nodes.

\section{DISCUSSION}

As one of the minimally invasive surgeries, interstitial brachytherapy is of increasing importance in the treatment of cancer $[1,14]$. At present, the emerged commercial navigation systems are not mature and have their own limitations. Most of the preoperative treatment planning is completed manually, which is time-consuming, non-repeatable and with subjective. Once the deviation of seed placement occurs in the middle of the procedure, it is difficult to adjust the original treatment planning in real time, leading to treatment failure. Another important issue with clinical relevance is the dosimetric uncertainty which renders intraoperative dosimetric update difficult and inaccurate. This is because some implanted radioactive seeds are unidentified or hidden due to overlapping or poor imaging, making captures of the coordinates of the seeds unavailable. We can solve this problem by making segmenting algorithms more precise, using novel image fusion techniques, or making seeds more visible for the guiding image modality. For soft tissues or organs, new algorithms are required to calculate respiratory displacement and incorporate these parameters to the whole navigation system. Registration is the key to ensure the precision, but the time needed for registration is the longest. Thus, increasing registration speed is another problem that needs to be solved in the future. In addition, to improve the interoperability of devices and software for image-guided therapy (IGT) and promote the transition from research prototypes to clinical use, a need for standardized communication among devices and software to share data such as target locations, images and device status is highlighted. There have been sporadic efforts to standardize the interconnections between medical devices and software. Tokuda et al. [110] proposed a new, open, extensible yet simple network communication protocol named OpenIGTLink. It was designed for use in the Application Layer on the TCP/IP stack, while allowing developers to implement it for other network models, such as the User Datagram Protocol. The results of performance tests and use-case evaluations showed that this protocol was capable of handling data with sufficient time resolution and latency. It transferred position data with submillisecond latency up to $1024 \mathrm{fps}$ and images with latency of $<10 \mathrm{~ms}$ at $32 \mathrm{fps}$.

To date, with the development of molecular imaging (MI) technology, we believe that image-guided brachytherapy will be moving into a new phase. Molecular imaging and image-fusion techniques can synthesize anatomical, metabolic, and functional information to guide clinicians in their decision-making [111]. The combination of full-course molecular imaging and intraoperative navigation can assist clinicians to achieve complete elimination of tumors by defining tumor extent and visualizing any residual tumor tissue.

In the future, our goals are to merge the multimodality-based images into a single model, to incorporate the use of novel MI agents to detect tumors, to increase accuracy of navigation systems, and to perform real-time evaluation of seed placement and dosimetry update. To accelerate clinical translation and evaluate the real effectiveness of these techniques, further clinical trials with quantitative clinical data are necessary.

\section{CONFLICTS OF INTEREST}

None. 


\section{FUNDING}

This work was funded by the National Natural Science Foundation of China [No. 81471683, No. 81671710].

\section{REFERENCES}

1. Li W, Guan J, Yang L, Zheng X, Yu Y, Jiang J. Iodine-125 brachytherapy improved overall survival of patients with inoperable stage III/IV non-small cell lung cancer versus the conventional radiotherapy. Med Oncol. 2015; 32:395. https://doi.org/10.1007/s12032-014-0395-8.

2. Yang H, Liu YH, Xu L, Liu LH. Efficacy of permanent iodine-125 seed implants and gemcitabine chemotherapy in patients with platinum- resistant recurrent ovarian carcinoma. Asian Pac J Cancer Prev. 2014; 15:9009-13. https://doi.org/10.7314/APJCP.2014.15.20.9009.

3. Wang J, Jiang Y, Li J, Tian S, Ran W, Xiu D. Intraoperative ultrasound-guided iodine-125 seed implantation for unresectable pancreatic carcinoma. J Exp Clin Cancer Res. 2009; 28:88. https://doi.org/10.1186/1756-9966-28-88.

4. Nag S, DeHaan M, Scruggs G, Mayr N, Martin EW. Longterm follow-up of patients of intrahepatic malignancies treated with iodine-125 brachytherapy. Int J Radiat Oncol Biol Phys. 2006; 64:736-44. https://doi.org/10.1016/j. ijrobp.2005.08.029.

5. Zhongmin W, Yu L, Fenju L, Kemin C, Gang H. Clinical efficacy of CT-guided iodine-125 seed implantation therapy in patients with advanced pancreatic cancer. Eur Radiol. 2010；20:1786-91. https://doi.org/10.1007/s00330-0091703-0.

6. Holm HH, Juul N, Pedersen JF, Hansen H, Strøyer I. Transperineal 125iodine seed implantation in prostatic cancer guided by transrectal ultrasonography. J Urol. 1983; 130:28386. https://doi.org/10.1016/S0022-5347(17)51108-8.

7. Blasko JC, Grimm PD, Ragde H. Brachytherapy and Organ Preservation in the Management of Carcinoma of the Prostate. Semin Radiat Oncol. 1993; 3:240-49. https://doi. org/10.1016/S1053-4296(05)80121-3.

8. Grimm PD, Blasko JC, Sylvester JE, Meier RM, Cavanagh W. 10-year biochemical (prostate-specific antigen) control of prostate cancer with (125)I brachytherapy. Int J Radiat Oncol Biol Phys. 2001; 51:31-40. https://doi.org/10.1016/ S0360-3016(01)01601-7.

9. Merrick GS, Butler WM, Galbreath RW, Lief JH. Fiveyear biochemical outcome following permanent interstitial brachytherapy for clinical T1-T3 prostate cancer. Int J Radiat Oncol Biol Phys. 2001; 51:41-48. https://doi. org/10.1016/S0360-3016(01)01594-2.

10. Zelefsky MJ, Wallner KE, Ling CC, Raben A, Hollister T, Wolfe T, Grann A, Gaudin P, Fuks Z, Leibel SA. Comparison of the 5-year outcome and morbidity of threedimensional conformal radiotherapy versus transperineal permanent iodine-125 implantation for early-stage prostatic cancer. J Clin Oncol. 1999; 17:517-22. https://doi. org/10.1200/JCO.1999.17.2.517.

11. McGill CS, Schwartz JA, Moore JZ, McLaughlin PW, Shih AJ. Effects of insertion speed and trocar stiffness on the accuracy of needle position for brachytherapy. Med Phys. 2012; 39:1811-17. https://doi.org/10.1118/1.3689812.

12. Taschereau R, Pouliot J, Roy J, Tremblay D. Seed misplacement and stabilizing needles in transperineal permanent prostate implants. Radiother Oncol. 2000; 55:59-63. https://doi.org/10.1016/S0167-8140(00)00162-6.

13. Haack S, Kallehauge JF, Jespersen SN, Lindegaard JC, Tanderup K, Pedersen EM. Correction of diffusion-weighted magnetic resonance imaging for brachytherapy of locally advanced cervical cancer. Acta Oncol. 2014; 53:1073-78. https://doi.org/10.3109/0284186X.2014.938831.

14. Wierzbicka M, Bartochowska A, Strnad V, Strojan P, Mendenhall WM, Harrison LB, Rinaldo A, Sahai P, Wiegand S, Ferlito A. The role of brachytherapy in the treatment of squamous cell carcinoma of the head and neck. Eur Arch Otorhinolaryngol. 2016; 273:269-76. https://doi. org/10.1007/s00405-014-3332-8.

15. Petereit DG, Omidpanah A, Boylan A, Kussman P, Baldwin D, Banik D, Minton M. The impact of breast patient navigation on breast preservation rates. Int J Radiat Oncol. 2014; 90:S274-75. https://doi.org/10.1016/j. ijrobp.2014.05.940.

16. Zhenjia L, Lianxiang X, Lebin W, Xianghong Y, Ximing W, Weitao D, Xujian H. Brachytherapy by CT-guided percutaneous paracentesis implantation of I-125 seed for treating lung cancer. Technol Cancer Res Treat. 2006; 6:574-77.

17. Horsley V, Clarke RH. The structure and functions of the cerebellum examined by a new method. Brain. 1908; 31:45-124. https://doi.org/10.1093/brain/31.1.45.

18. Nolden M, Zelzer S, Seitel A, Wald D, Muller M, Franz AM, Maleike D, Fangerau M, Baumhauer M, Maier-Hein L, Maier-Hein KH, Meinzer HP, Wolf I. The Medical Imaging Interaction Toolkit: challenges and advances: 10 years of open-source development. Int J Comput Assist Radiol Surg. 2013; 8:607-20.

19. März K, Franz AM, Seitel A, Winterstein A, Bendl R, Zelzer S, Nolden M, Meinzer HP, Maier-Hein L. MITK-US: realtime ultrasound support within MITK. Int J CARS. 2014; 9:411-20. https://doi.org/10.1007/s11548-013-0962-z.

20. Fedorov A, Beichel R, Kalpathy-Cramer J, Finet J, FillionRobin JC, Pujol S, Bauer C, Jennings D, Fennessy F, Sonka M, Buatti J, Aylward S, Miller JV, et al. 3D Slicer as an image computing platform for the Quantitative Imaging Network. Magn Reson Imaging. 2012; 30:1323-41. https:// doi.org/10.1016/j.mri.2012.05.001.

21. Enquobahrie A, Cheng P, Gary K, Ibanez L, Gobbi D, Lindseth F, Yaniv Z, Aylward S, Jomier J, Cleary K. The image-guided surgery toolkit IGSTK: an open source C++ software toolkit. J Digit Imaging. 2007 (Suppl 1); 20:21-33. https://doi.org/10.1007/s10278-007-9054-3. 
22. Krempien R, Hassfeld S, Kozak J, Tuemmler HP, Däuber S, Treiber M, Debus J, Harms W. Frameless image guidance improves accuracy in three-dimensional interstitial brachytherapy needle placement. Int J Radiat Oncol Biol Phys. 2004; 60:1645-51. https://doi.org/10.1016/j. ijrobp.2004.07.670.

23. Liu FY, Yu XL, Liang P, Cheng ZG, Han ZY, Dong BW, Zhang XH. Microwave ablation assisted by a real-time virtual navigation system for hepatocellular carcinoma undetectable by conventional ultrasonography. Eur J Radiol. 2012; 81:1455-59. https://doi.org/10.1016/j. ejrad.2011.03.057.

24. Wu W, Xue J, Liang P, Cheng Z, Zhang M, Mu M, Qi C. The assistant function of three-dimensional information for I125 particle implantation. IEEE J Biomed Health Inform. 2014; 18:77-82. https://doi.org/10.1109/JBHI.2013.2259180.

25. Liu F, Liang P, Yu X, Lu T, Cheng Z, Lei C, Han Z. A threedimensional visualisation preoperative treatment planning system in microwave ablation for liver cancer: a preliminary clinical application. Int J Hyperthermia. 2013; 29:671-77. https://doi.org/10.3109/02656736.2013.834383.

26. Nath R, Bice WS, Butler WM, Chen Z, Meigooni AS, Narayana V, Rivard MJ, Yu Y, and American Association of Physicists in Medicine. AAPM recommendations on dose prescription and reporting methods for permanent interstitial brachytherapy for prostate cancer: report of Task Group 137. Med Phys. 2009; 36:5310-22. https://doi. org/10.1118/1.3246613.

27. Davis BJ, Horwitz EM, Lee WR, Crook JM, Stock RG, Merrick GS, Butler WM, Grimm PD, Stone NN, Potters L, Zietman AL, Zelefsky MJ, and American Brachytherapy Society. American Brachytherapy Society consensus guidelines for transrectal ultrasound-guided permanent prostate brachytherapy. Brachytherapy. 2012; 11:6-19. https://doi.org/10.1016/j.brachy.2011.07.005.

28. Buyyounouski MK, Davis BJ, Prestidge BR, Shanahan TG, Stock RG, Grimm PD, Demanes DJ, Zaider M, Horwitz EM. A survey of current clinical practice in permanent and temporary prostate brachytherapy: 2010 update. Brachytherapy. 2012; 11:299-305. https://doi.org/10.1016/j. brachy.2011.12.012.

29. Zourari K, Pantelis E, Moutsatsos A, Sakelliou L, Georgiou E, Karaiskos P, Papagiannis P. Dosimetric accuracy of a deterministic radiation transport based (192)Ir brachytherapy treatment planning system. Part III. Comparison to Monte Carlo simulation in voxelized anatomical computational models. Med Phys. 2013; 40:011712. https://doi.org/10.1118/1.4770275.

30. Jiang YR, Sykes ER. A 3D computer-assisted treatment planning system for breast cancer brachytherapy treatment. Int J CARS. 2015; 10:373-81. https://doi.org/10.1007/ s11548-014-1092-y.

31. Mikell JK, Klopp AH, Price M, Mourtada F. Commissioning of a grid-based Boltzmann solver for cervical cancer brachytherapy treatment planning with shielded colpostats. Brachytherapy. 2013; 12:645-53. https://doi.org/10.1016/j. brachy.2013.04.007.

32. Mikell JK, Mourtada F. Dosimetric impact of an 192Ir brachytherapy source cable length modeled using a gridbased Boltzmann transport equation solver. Med Phys. 2010; 37:4733-43. https://doi.org/10.1118/1.3478278.

33. Deufel CL, Furutani KM. Quality assurance for high dose rate brachytherapy treatment planning optimization: using a simple optimization to verify a complex optimization. Phys Med Biol. 2014; 59:525-40. https://doi.org/10.1088/00319155/59/3/525.

34. Fonseca GP, Reniers B, Landry G, White S, Bellezzo M, Antunes PC, de Sales CP, Welteman E, Yoriyaz H, Verhaegen F. A medical image-based graphical platformfeatures, applications and relevance for brachytherapy. Brachytherapy. 2014; 13:632-39. https://doi.org/10.1016/j. brachy.2014.07.004.

35. Ali SN, Patel R, Samani A. Ct-enhanced us image of lung's tumor for image-guided LDR brachytherapy. Technol Cancer Res Treat. 2012; 11:518.

36. Grimson WE, Kikinis R, Jolesz FA, Black PM. Imageguided surgery. Sci Am. 1999; 280:62-69. https://doi. org/10.1038/scientificamerican0699-62.

37. Tauchi R, Imagama S, Sakai Y, Ito Z, Ando K, Muramoto A, Matsui H, Matsumoto T, Ishiguro N. The correlation between cervical range of motion and misplacement of cervical pedicle screws during cervical posterior spinal fixation surgery using a CT-based navigation system. Eur Spine J. 2013; 22:1504-08. https://doi.org/10.1007/s00586013-2719-3.

38. Caversaccio M, Langlotz F, Nolte LP, Häusler R. Impact of a self-developed planning and self-constructed navigation system on skull base surgery: 10 years experience. Acta Otolaryngol. 2007; 127:403-07. https://doi. org/10.1080/00016480601002104.

39. Shamir RR, Joskowicz L. Geometrical analysis of registration errors in point-based rigid-body registration using invariants. Med Image Anal. 2011; 15:85-95. https:// doi.org/10.1016/j.media.2010.07.010.

40. Ren Y, Bu R, Zhang L, Huang X, Li Y. Implantation of radioactive particles into the cranial base and orbital apex with the use of a magnetic resonance imaging-based surgical navigation system. Oral Surg Oral Med Oral Pathol Oral Radiol. 2013; 116:e473-77. https://doi.org/10.1016/j. oooo.2012.01.047.

41. Gumprecht HK, Widenka DC, Lumenta CB. BrainLab VectorVision Neuronavigation System: technology and clinical experiences in 131 cases. Neurosurgery. 1999; 44:97-104; discussion 104-5.

42. Crum WR, Hartkens T, Hill DL. Non-rigid image registration: theory and practice. Br J Radiol. 2004 (suppl_2); 77:S140-53. https://doi.org/10.1259/ bjr/25329214. 
43. Christensen GE, Johnson HJ. Consistent image registration. IEEE Trans Med Imaging. 2001; 20:568-82. https://doi. org/10.1109/42.932742.

44. Leow A, Huang SC, Geng A, Becker J, Davis S, Toga A, Thompson P. Inverse consistent mapping in $3 \mathrm{D}$ deformable image registration: its construction and statistical properties. Inf Process Med Imaging. 2005; 19:493-503.

45. Naini AS, Pierce G, Lee TY, Patel RV, Samani A. CT image construction of a totally deflated lung using deformable model extrapolation. Med Phys. 2011; 38:872-83. https:// doi.org/10.1118/1.3531985.

46. Fitzpatrick JM, West JB. The distribution of target registration error in rigid-body point-based registration. IEEE Trans Med Imaging. 2001; 20:917-27. https://doi. org/10.1109/42.952729.

47. Ji JX, Pan H, Liang ZP. Further analysis of interpolation effects in mutual information-based image registration. IEEE Trans Med Imaging. 2003; 22:1131-40. https://doi. org/10.1109/TMI.2003.816957.

48. Kainz B, Steinberger M, Wein W, Kuklisova-Murgasova M, Malamateniou C, Keraudren K, Torsney-Weir T, Rutherford M, Aljabar P, Hajnal JV, Rueckert D. Fast Volume Reconstruction From Motion Corrupted Stacks of 2D Slices. IEEE Trans Med Imaging. 2015; 34:1901-13. https://doi.org/10.1109/TMI.2015.2415453.

49. van der Bom MJ, Bartels LW, Gounis MJ, Homan R, Timmer J, Viergever MA, Pluim JP. Robust initialization of 2D-3D image registration using the projection-slice theorem and phase correlation. Med Phys. 2010; 37:1884-92. https:// doi.org/10.1118/1.3366252.

50. Desplanques M, Tagaste B, Fontana G, Pella A, Riboldi M, Fattori G, Donno A, Baroni G, Orecchia R. A comparative study between the imaging system and the optical tracking system in proton therapy at CNAO. J Radiat Res (Tokyo). 2013 (Suppl 1); 54:i129-35. https://doi.org/10.1093/jrr/ rrt043.

51. Hamming NM, Daly MJ, Irish JC, Siewerdsen JH. Automatic image-to-world registration based on x-ray projections in cone-beam CT-guided interventions. Med Phys. 2009; 36:1800-12. https://doi.org/10.1118/1.3117609.

52. Boutaleb S, Racine E, Fillion O, Bonillas A, Hautvast G, Binnekamp D, Beaulieu L. Performance and suitability assessment of a real-time 3D electromagnetic needle tracking system for interstitial brachytherapy. J Contemp Brachytherapy. 2015; 7:280-89. https://doi.org/10.5114/ jcb.2015.54062.

53. Sadjadi H, Hashtrudi-Zaad K, Fichtinger G. Simultaneous Electromagnetic Tracking and Calibration for Dynamic Field Distortion Compensation. IEEE Trans Biomed Eng. 2016; 63:1771-81. https://doi.org/10.1109/ TBME.2015.2502138.

54. Trejos AL, Lin AW, Pytel MP, Patel RV, Malthaner RA. Robot-assisted minimally invasive lung brachytherapy. Int J Med Robot. 2007; 3:41-51. https://doi.org/10.1002/rcs.126.
55. Franz AM, Haidegger T, Birkfellner W, Cleary K, Peters TM, Maier-Hein L. Electromagnetic tracking in medicine - a review of technology, validation, and applications. IEEE Trans Med Imaging. 2014; 33:1702-25. https://doi.org/10.1109/TMI.2014.2321777.

56. Feichtinger M, Pau M, Zemann W, Aigner RM, Kärcher $\mathrm{H}$. Intraoperative control of resection margins in advanced head and neck cancer using a 3D-navigation system based on PET/CT image fusion. J Craniomaxillofac Surg. 2010; 38:589-94. https://doi.org/10.1016/j.jcms.2010.02.004.

57. Day JS, Dumas GA, Murdoch DJ. Evaluation of a longrange transmitter for use with a magnetic tracking device in motion analysis. J Biomech. 1998; 31:957-61. https://doi. org/10.1016/S0021-9290(98)00089-X.

58. Franz AM, März K, Hummel J, Birkfellner W, Bendl R, Delorme S, Schlemmer HP, Meinzer HP, Maier-Hein L. Electromagnetic tracking for US-guided interventions: standardized assessment of a new compact field generator. Int J CARS. 2012; 7:813-18. https://doi.org/10.1007/ s11548-012-0740-3.

59. Hummel JB, Bax MR, Figl ML, Kang Y, Maurer C Jr, Birkfellner WW, Bergmann H, Shahidi R. Design and application of an assessment protocol for electromagnetic tracking systems. Med Phys. 2005; 32:2371-79.

60. Leong S, Ju H, Marshall H, Bowman R, Yang I, Ree AM, Saxon C, Fong KM. Electromagnetic navigation bronchoscopy: A descriptive analysis. J Thorac Dis. 2012; 4:173-85.

61. Koele W, Stammberger H, Lackner A, Reittner P. Image guided surgery of paranasal sinuses and anterior skull base-five years experience with the InstaTrak-System. Rhinology. 2002; 40:1-9.

62. McVicar J, Niazi AU, Murgatroyd H, Chin KJ, Chan VW. Novice performance of ultrasound-guided needling skills: effect of a needle guidance system. Reg Anesth Pain Med. 2015; 40:150-53. https://doi.org/10.1097/ AAP.0000000000000209.

63. Wong SW, Niazi AU, Chin KJ, Chan VW. Real-time ultrasound-guided spinal anesthesia using the SonixGPS ${ }^{\circledR}$ needle tracking system: a case report. Can J Anaesth. 2013; 60:50-53. https://doi.org/10.1007/s12630-012-9809-2.

64. Appelbaum L, Solbiati L, Sosna J, Nissenbaum Y, Greenbaum N, Goldberg SN. Evaluation of an electromagnetic image-fusion navigation system for biopsy of small lesions: assessment of accuracy in an in vivo swine model. Acad Radiol. 2013; 20:209-17. https://doi. org/10.1016/j.acra.2012.09.020.

65. Xu HX, Lu MD, Liu LN, Guo LH. Magnetic navigation in ultrasound-guided interventional radiology procedures. Clin Radiol. 2012; 67:447-54. https://doi.org/10.1016/j. crad.2011.10.015.

66. Yang EY, Polsani VR, Washburn MJ, Zang W, Hall AL, Virani SS, Hodge MD, Parker D, Kerwin WS, Lawrie GM, Garami Z, Ballantyne CM, Morrisett JD, Nambi V. Real- 
time co-registration using novel ultrasound technology: ex vivo validation and in vivo applications. J Am Soc Echocardiogr. 2011; 24:720-28. https://doi.org/10.1016/j. echo.2011.02.003.

67. Penzkofer T, Bruners P, Isfort P, Schoth F, Günther RW, Schmitz-Rode T, Mahnken AH. Free-hand CT-based electromagnetically guided interventions: accuracy, efficiency and dose usage. Minim Invasive Ther Allied Technol. 2011; 20:226-33. https://doi.org/10.3109/136457 06.2011 .553256 .

68. Wray CD, Kraemer DL, Yang T, Poliachik SL, Ko AL, Poliakov A, Hebb AO, Novotny EJ, Ojemann JG. Freehand placement of depth electrodes using electromagnetic frameless stereotactic guidance. J Neurosurg Pediatr. 2011; 8:464-67. https://doi.org/10.3171/2011.8.PEDS11143.

69. Elfring R, de la Fuente M, Radermacher K. Assessment of optical localizer accuracy for computer aided surgery systems. Comput Aided Surg. 2010; 15:1-12. https://doi. org/10.3109/10929081003647239.

70. Clarke JV, Deakin AH, Nicol AC, Picard F. Measuring the positional accuracy of computer assisted surgical tracking systems. Comput Aided Surg. 2010; 15:13-18. https://doi. org/10.3109/10929081003775774.

71. Ricke J, Thormann M, Ludewig M, Jungnickel K, Grosser O, Wybranski C, Peters N, Hass P, Bunke J, Fischbach F. MR-guided liver tumor ablation employing open high-field 1.0T MRI for image-guided brachytherapy. Eur Radiol. 2010; 20:1985-93. https://doi.org/10.1007/s00330-0101751-5.

72. Zhang S, Jiang S, Yang Z, Liu R. 2D Ultrasound and 3D MR Image Registration of the Prostate for Brachytherapy Surgical Navigation. Medicine (Baltimore). 2015; 94:e1643. https://doi.org/10.1097/MD.0000000000001643.

73. Saw CB, Chen H, Beatty RE, Wagner H Jr. Multimodality image fusion and planning and dose delivery for radiation therapy. Med Dosim. 2008; 33:149-55. https://doi. org/10.1016/j.meddos.2008.03.001.

74. Polo A, Salembier C, Venselaar J, Hoskin P, and PROBATE group of the GEC ESTRO. Review of intraoperative imaging and planning techniques in permanent seed prostate brachytherapy. Radiother Oncol. 2010; 94:12-23. https:// doi.org/10.1016/j.radonc.2009.12.012.

75. Giesel FL, Mehndiratta A, Locklin J, McAuliffe MJ, White S, Choyke PL, Knopp MV, Wood BJ, Haberkorn U, von Tengg-Kobligk H. Image fusion using CT, MRI and PET for treatment planning, navigation and follow up in percutaneous RFA. Exp Oncol. 2009; 31:106-14.

76. Katayama N, Takemoto M, Yoshio K, Katsui K, Uesugi T, Nasu Y, Matsushita T, Kaji M, Kumon H, Kanazawa S. T2*weighted image/T2-weighted image fusion in postimplant dosimetry of prostate brachytherapy. J Radiat Res (Tokyo). 2011; 52:680-84. https://doi.org/10.1269/jrr.11011.

77. Steffen IG, Wust P, Rühl R, Grieser C, Schnapauff D, Lüdemann L, Grabik W, Ricke J, Amthauer H, Hamm B,
Hänninen EL, Denecke T. Value of combined PET/CT for radiation planning in CT-guided percutaneous interstitial high-dose-rate single-fraction brachytherapy for colorectal liver metastases. Int J Radiat Oncol Biol Phys. 2010; 77:1178-85. https://doi.org/10.1016/j.ijrobp.2009.06.047.

78. Poncet D, Arnoux V, Descotes JL, Rambeaud JJ, Verry C, Terrier N, Boillot B, Dubreuil J, Lanchon C, Carnicelli D, Fiard G, Long JA. [Biochemical recurrence after curative treatment for localized prostate cancer: performance of choline PET/CT in the assessment of local recurrence]. [Article in French]. Prog Urol. 2015; 25:325-30. https:// doi.org/10.1016/j.purol.2015.01.018.

79. Bentsion DL, Gvozdev PB, Sakovich VP, Fialko NV, Kolotvinov VS, Baiankina SN. [The first experience in interstitial brachytherapy for primary and metastatic tumors of the brain]. [Article in Russian]. Zh Vopr Neirokhir Im N N Burdenko. 2006; 18-21; discussion 21.

80. Li J, Yu M, Xiao Y, Yang L, Zhang J, Ray E, Yang X. Computed tomography fluoroscopy-guided percutaneous (125)I seed implantation for safe, effective and real-time monitoring radiotherapy of inoperable stage T1-3N0M0 non-small-cell lung cancer. Mol Clin Oncol. 2013; 1:101924. https://doi.org/10.3892/mco.2013.171.

81. Tagliaferri L, Bussu F, Rigante M, Gambacorta MA, Autorino R, Mattiucci GC, Fionda B, Miccichè F, Placidi E, Balducci M, Galli J, Valentini V, Paludetti G, Kovacs G. Endoscopy-guided brachytherapy for sinonasal and nasopharyngeal recurrences. Brachytherapy. 2015; 14:41925. https://doi.org/10.1016/j.brachy.2014.11.012.

82. Pouw B, de Wit-van der Veen LJ, van Duijnhoven F, Rutgers EJ, Stokkel MP, Valdés Olmos RA, Vrancken Peeters MJ. Intraoperative 3D Navigation for Single or Multiple 125I-Seed Localization in Breast-Preserving Cancer Surgery. Clin Nucl Med. 2016; 41:e216-20. https:// doi.org/10.1097/RLU.0000000000001081.

83. Li M, Ballhausen H, Hegemann NS, Ganswindt U, Manapov F, Tritschler S, Roosen A, Gratzke C, Reiner M, Belka C. A comparative assessment of prostate positioning guided by three-dimensional ultrasound and cone beam CT. Radiat Oncol. 2015; 10:82. https://doi.org/10.1186/s13014015-0380-1.

84. Scott MT, Stoyanova R, Abramowitz MC, Casillas VJ, Ishkanian A, Kwon D, Lynne C, Pollack A. MRI ultrasound fusion-guided biopsy of the prostate: results of initial experience in a radiation oncology department. Int $\mathrm{J}$ Radiat Oncol. 2014; 90:S207-08. https://doi.org/10.1016/j. ijrobp.2014.05.769.

85. Hu S, Shi X, Chen Y, Huang W, Song Q, Lin X, Liu Y, Chen K, Wang Z. Functional imaging of interstitial brachytherapy in pancreatic carcinoma xenografts using spectral CT: how does iodine concentration correlate with standardized uptake value of (18)FDG-PET-CT? Br J Radiol. 2016; 89:20150573. https://doi.org/10.1259/bjr.20150573.

86. Werner MK, Brechtel K, Beyer T, Dittmann H, Pfannenberg C, Kupferschläger J. PET/CT for the assessment and 
quantification of (90)Y biodistribution after selective internal radiotherapy (SIRT) of liver metastases. Eur J Nucl Med Mol Imaging. 2010; 37:407-08. https://doi. org/10.1007/s00259-009-1317-4.

87. Peppa V, Pappas E, Major T, Takácsi-Nagy Z, Pantelis E, Papagiannis P. On the impact of improved dosimetric accuracy on head and neck high dose rate brachytherapy. Radiother Oncol. 2016; 120:92-97. https://doi. org/10.1016/j.radonc.2016.01.022.

88. Chi C, Ye J, Ding H, He D, Huang W, Zhang GJ, Tian J. Use of indocyanine green for detecting the sentinel lymph node in breast cancer patients: from preclinical evaluation to clinical validation. PLoS One. 2013; 8:e83927. https:// doi.org/10.1371/journal.pone.0083927.

89. Villeirs GM, De Meerleer GO. Magnetic resonance imaging (MRI) anatomy of the prostate and application of MRI in radiotherapy planning. Eur J Radiol. 2007; 63:361-68. https://doi.org/10.1016/j.ejrad.2007.06.030.

90. Jolesz FA. Future perspectives for intraoperative MRI. Neurosurg Clin N Am. 2005; 16:201-13. https://doi. org/10.1016/j.nec.2004.07.011.

91. Tanderup K, Viswanathan AN, Kirisits C, Frank SJ. Magnetic resonance image guided brachytherapy. Semin Radiat Oncol. 2014; 24:181-91. https://doi.org/10.1016/j. semradonc.2014.02.007.

92. Buch K, Morancy T, Kaplan I, Qureshi MM, Hirsch AE, Rofksy NM, Holupka E, Oismueller R, Hawliczek R, Helbich TH, Bloch BN. Improved dosimetry in prostate brachytherapy using high resolution contrast enhanced magnetic resonance imaging: a feasibility study. J Contemp Brachytherapy. 2015; 6:337-43.

93. Nesvacil N, Potter R, Sturdza A, Hegazy N, Federico $\mathrm{M}$, Kirisits C. Adaptive image guided brachytherapy for cervical cancer: a combined MRI-/CT-planning technique with MRI only at first fraction. Radiother Oncol. 2013; 107:75-81.

94. Albert JM, Swanson DA, Pugh TJ, Zhang M, Bruno TL, Kudchadker RJ, Frank SJ. Magnetic resonance imagingbased treatment planning for prostate brachytherapy. Brachytherapy. 2013; 12:30-37. https://doi.org/10.1016/j. brachy.2012.03.009.

95. Owrangi AM, Prisciandaro JI, Soliman A, Ravi A, Song WY. Magnetic resonance imaging-guided brachytherapy for cervical cancer: initiating a program. J Contemp Brachytherapy. 2015; 7:417-22. https://doi.org/10.5114/ jcb.2015.55541.

96. Viswanathan AN, Dimopoulos J, Kirisits C, Berger D, Pötter R. Computed tomography versus magnetic resonance imaging-based contouring in cervical cancer brachytherapy: results of a prospective trial and preliminary guidelines for standardized contours. Int J Radiat Oncol Biol Phys. 2007; 68:491-98. https://doi.org/10.1016/j.ijrobp.2006.12.021.

97. Doemer A, Chetty IJ, Glide-Hurst C, Nurushev T, Hearshen D, Pantelic M, Traughber M, Kim J, Levin K, Elshaikh MA, Walker E, Movsas B. Evaluating organ delineation, dose calculation and daily localization in an open-MRI simulation workflow for prostate cancer patients. Radiat Oncol. 2015; 10:37. https://doi.org/10.1186/s13014-0140309-0.

98. Wybranski C, Eberhardt B, Fischbach K, Fischbach F, Walke M, Hass P, Röhl FW, Kosiek O, Kaiser M, Pech M, Lüdemann L, Ricke J. Accuracy of applicator tip reconstruction in MRI-guided interstitial 192Ir-high-doserate brachytherapy of liver tumors. Radiother Oncol. 2015; 115:72-77. https://doi.org/10.1016/j.radonc.2015.01.018.

99. Owrangi AM, Jolly S, Balter JM, Cao Y, Maturen KE, Young L, Zhu T, Prisciandaro JI. Clinical implementation of MR-guided vaginal cylinder brachytherapy. J Appl Clin Med Phys. 2015; 16:490-500.

100. Hu Y, Esthappan J, Mutic S, Richardson S, Gay HA, Schwarz JK, Grigsby PW. Improve definition of titanium tandems in MR-guided high dose rate brachytherapy for cervical cancer using proton density weighted MRI. Radiat Oncol. 2013; 8:16. https://doi.org/10.1186/1748-717X-8-16.

101. Kim Y, Muruganandham M, Modrick JM, Bayouth JE. Evaluation of artifacts and distortions of titanium applicators on 3.0-Tesla MRI: feasibility of titanium applicators in MRI-guided brachytherapy for gynecological cancer. Int J Radiat Oncol Biol Phys. 2011; 80:947-55. https://doi.org/10.1016/j.ijrobp.2010.07.1981.

102. Al-Halabi H, Portelance L, Duclos M, Reniers B, Bahoric B, Souhami L. Cone beam CT-based three-dimensional planning in high-dose-rate brachytherapy for cervical cancer. Int J Radiat Oncol Biol Phys. 2010; 77:1092-97. https://doi.org/10.1016/j.ijrobp.2009.06.036.

103. Zelefsky MJ, Worman M, Cohen GN, Pei X, Kollmeier M, Yamada J, Cox B, Zhang Z, Bieniek E, Dauer L, Zaider M. Real-time intraoperative computed tomography assessment of quality of permanent interstitial seed implantation for prostate cancer. Urology. 2010; 76:1138-42. https://doi. org/10.1016/j.urology.2010.01.067.

104. Pokhrel D, Murphy MJ, Todor DA, Weiss E, Williamson JF. Clinical application and validation of an iterative forward projection matching algorithm for permanent brachytherapy seed localization from conebeam-CT x-ray projections. Med Phys. 2010; 37:5092-101. https://doi. org/10.1118/1.3480962.

105. Pokhrel D, Murphy MJ, Todor DA, Weiss E, Williamson JF. Reconstruction of brachytherapy seed positions and orientations from cone-beam CT x-ray projections via a novel iterative forward projection matching method. Med Phys. 2011; 38:474-86. https://doi.org/10.1118/1.3528220.

106. Wang M, Ding H, Wang X, Wang G. Target visibility enhancement for C-arm cone beam CT-fluoroscopy-guided hepatic needle placement: implementation and accuracy evaluation. Int J CARS. 2015; 10:263-73. https://doi. org/10.1007/s11548-014-1070-4.

107. Amat di San Filippo C, Fichtinger G, Morris WJ, Salcudean SE, Dehghan E, Fallavollita P. Intraoperative segmentation of iodine and palladium radioactive sources 
in C-arm images. Int J CARS. 2014; 9:769-76. https://doi. org/10.1007/s11548-014-0983-2.

108. Floridi C, Muollo A, Fontana F, Rotolo N, Ierardi AM, Duka E, Pellegrino C, Carrafiello G. C-arm cone-beam computed tomography needle path overlay for percutaneous biopsy of pulmonary nodules. Radiol Med (Torino). 2014; 119:820-27. https://doi.org/10.1007/s11547-014-0406-z.

109. Abi-Jaoudeh N, Venkatesan AM, Van der Sterren W, Radaelli A, Carelsen B, Wood BJ. Clinical experience with cone-beam CT navigation for tumor ablation. J Vasc Interv Radiol. 2015; 26:214-19. https://doi.org/10.1016/j. jvir.2014.10.049.
110. Tokuda J, Fischer GS, Papademetris X, Yaniv Z, Ibanez L, Cheng P, Liu H, Blevins J, Arata J, Golby AJ, Kapur T, Pieper S, Burdette EC, et al. OpenIGTLink: an open network protocol for image-guided therapy environment. Int J Med Robot. 2009; 5:423-34. https://doi.org/10.1002/ res. 274.

111. Su N, Dang Y, Liang G, Liu G. Iodine-125-labeled cRGDgold nanoparticles as tumor-targeted radiosensitizer and imaging agent. Nanoscale Res Lett. 2015; 10:160. https:// doi.org/10.1186/s11671-015-0864-9. 